\title{
A prospective study of eating away-from-home meals and weight gain in a Mediterranean population: the SUN (Seguimiento Universidad de Navarra) cohort
}

\author{
Maira Bes-Rastrollo ${ }^{1, *}$, Francisco Javier Basterra-Gortari ${ }^{1,2}$, Almudena Sánchez-Villegas ${ }^{1,3}$, \\ Amelia Marti ${ }^{4}$, José Alfredo Martínez ${ }^{4}$ and Miguel Angel Martínez-González ${ }^{1}$ \\ 'Department of Preventive Medicine and Public Health, University of Navarra, c/ Irunlarrea, 1 Ed. Investigación, \\ E-3 1008 Pamplona (Navarra), Spain: ${ }^{2}$ Department of Endocrinology, Hospital of Navarra, Pamplona, Spain: \\ ${ }^{3}$ Department of Clinical Sciences, University of Las Palmas, Las Palmas, Spain: ${ }^{4}$ Department of Nutrition, Food \\ Science, Physiology, and Toxicology, University of Navarra, Pamplona, Spain
}

Submitted 4 August 2008: Accepted 1 November 2009: First published online 3 December 2009

\begin{abstract}
Objective: The traditional Mediterranean food pattern is more easily preserved when meals are eaten at home; however, as a result of recent socio-economic changes, away-from-home meal consumption has increased rapidly in Mediterranean countries. Little research has been conducted so far to investigate the long-term health effects of these changes in the Mediterranean area.

Design: In a prospective Spanish dynamic cohort of 9182 university graduates (the SUN Study; Seguimiento Universidad de Navarra, University of Navarra Followup) with a mean age of 37 years, followed up for an average of $4 \cdot 4$ years, we assessed the association between the frequency of eating out of home and weight gain or incident overweight/obesity. Dietary habits were assessed with an FFQ previously validated in Spain.

Results: During follow-up, eating-out consumers (two times or more per week) had higher average adjusted weight gain $(+129 \mathrm{~g} /$ year, $P<0 \cdot 001)$ and higher adjusted risk of gaining $2 \mathrm{~kg}$ or more per year (OR $=1 \cdot 36 ; 95 \% \mathrm{CI} 1 \cdot 13,1 \cdot 63)$ than non-eating-out consumers. Among participants with baseline BMI $<25 \mathrm{~kg} / \mathrm{m}^{2}$, we observed 855 new cases of overweight/obesity. Eating away-from-home meals was significantly associated with a higher risk of becoming overweight/obese (hazard ratio $=1 \cdot 33 ; 95 \%$ CI $1 \cdot 13,1 \cdot 57$ ).

Conclusions: A higher frequency of meals eaten out of home may play a role in the current obesity epidemic observed in some Mediterranean countries.
\end{abstract}

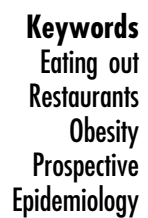

The traditional Mediterranean food pattern rich in plant foods and low in saturated fat has been associated with increased longevity and lower rates of chronic disease and cardiovascular risk factors ${ }^{(1-4)}$. This dietary pattern is mostly preserved when meals are eaten at home. The nutritional quality of foods consumed away from home is considerably poorer than the food eaten at home ${ }^{(5)}$. A Spanish study found that fast-food consumption was inversely associated with compliance with dietary reference intake guidelines. In addition, participants with the highest frequency (more than once per week) of eating a product from a fast-food outlet showed the lowest adherence to a traditional Mediterranean score ${ }^{(6)}$.

Socio-economic changes, such as an increased female involvement in the labour force, the adoption of longer work hours, an increase in commute time and the subsequent scarcity of time, have contributed to an increase in food consumption away from home ${ }^{(7,8)}$. Moreover, this increasing trend is very likely to continue growing in subsequent years. According to Euromonitor International, Spain is the largest consumer food-service market in the European Union in terms of value sales and has one of the highest numbers of outlets per capita in the world ${ }^{(9)}$. In addition, the largest growth in food service in Southern Europe during 2000-5 was for fast-food restaurants ${ }^{(9)}$.

Nowadays, obesity could be considered as one of the greatest pandemics in the world, including the Mediterranean countries ${ }^{(10)}$. Because of the excessive portion size of energy-dense foods in meals served in restaurants, it has been hypothesized that eating away from home may lead to a positive energy balance and thereby might be contributing to the current obesity pandemic ${ }^{(11)}$.

Studies on the association between away-from-home eating and obesity have only been performed during the last few years and most of these studies have been conducted in the USA. As a consequence, little is known 
about the role of eating away from home on the growing obesity epidemic in Mediterranean countries. Nevertheless, a recent cross-sectional study ${ }^{(12)}$ of a representative non-institutionalized Spanish population found no association between having one or more of the main meals away from home and obesity, suggesting that differences in the type of restaurants might explain this null association. No previous longitudinal study has evaluated this hypothesis in Mediterranean areas.

Our objective was to assess prospectively the association between away-from-home eating and the risk of weight gain (or becoming overweight/obese) in a Mediterranean cohort of university graduates.

\section{Methods}

\section{Study population}

The SUN Project (Seguimiento Universidad de Navarra, University of Navarra Follow-up) is a prospective cohort study designed to establish associations between diet and the occurrence of several disease and chronic conditions including obesity. Information is collected through selfadministered questionnaires sent by mail every 2 years. A detailed description of the study methods has been published elsewhere ${ }^{(13)}$.

The recruitment of participants, all of whom are university graduates, started in December 1999 and is permanently open, because this study was designed to be a dynamic cohort. In October 2007, the data set of the SUN Project included 18494 participants. All participants who completed a baseline assessment before October 2004 were eligible for the analyses ( $n$ 14 106). Among them, 733 did not answer the 2-year follow-up questionnaire after five mailings. We retained 13373 who successfully completed a follow-up questionnaire (94.8\% 2-year retention rate). Following the recommendations for conducting analyses in nutritional epidemiology ${ }^{(14)}$, participants who reported extreme (low or high) values for total energy intake $(<3349 \mathrm{~kJ} / \mathrm{d} \quad(<800 \mathrm{kcal} / \mathrm{d})$ for men, $<2093 \mathrm{~kJ} / \mathrm{d}(<500 \mathrm{kcal} / \mathrm{d})$ for women or $>16747 \mathrm{~kJ} / \mathrm{d}$ $(>4000 \mathrm{kcal} / \mathrm{d})$ for men, $>14659 \mathrm{~kJ} / \mathrm{d} \quad(>3500 \mathrm{kcal} / \mathrm{d})$ for women; $n$ 1301) were excluded. Participants who reported a diagnosis of CVD, diabetes or cancer at baseline or during follow-up were also excluded ( $n$ 1085), as were female participants who were pregnant at baseline or during follow-up ( $n$ 333). Participants with biologically implausible values for weight $(>170 \mathrm{~kg}$ ) or with missing values in variables of interest were also excluded. Finally, data from 9182 participants were available for the analyses. Of these, $36 \%$ of the population was followed up for an average of 6 years, $31 \%$ for an average of 4 years and $33 \%$ of the sample had on average 2 years of followup. Those participants excluded showed similar eatingout frequency and body-weight change $(P=0 \cdot 15$ and $P=0 \cdot 45$, respectively) to those included in the analysis.
The study was approved by the Institutional Review Board at the University of Navarra. Informed consent was implied by the voluntary completion of the baseline questionnaire.

\section{Assessment of diet and definition of eating away- from-bome meals}

Dietary habits were assessed through a baseline semiquantitative FFQ that had been validated in Spain ${ }^{(15)}$.

The questionnaire was based on typical portion sizes and had nine options for the average frequency of consumption in the previous year of 136 food items (ranging from 'never/almost never' to 'at least six times per day').

The FFQ included the following question: 'With which frequency do you have meals away from home?' with nine possible options ranging from 'never/almost never' to at 'least six times per day'. According to the distribution of the answers to this question and based on categories previously used in other studies, we classified the participants into three groups according to their frequency of eating out: (i) never/almost never to 1-3 times per month; (ii) 1 time per week; and (iii) 2 or more times per week.

Nutrient intake scores were computed using an ad boc computer program. A trained dietitian updated the nutrient databank using the most updated Spanish composition tables ${ }^{(16,17)}$. Fast-food group consumption was defined as the sum of sausages, hamburgers and pizza.

\section{Assessment of non-dietary variables}

The baseline assessment also included other questions (forty-six items for men and fifty-four for women) to assess medical history, health habits, and lifestyle and sociodemographic variables. Participants were classified as nonsmokers, former smokers or current smokers. Physical activity was assessed through a baseline questionnaire. The metabolic equivalent (MET) index per week was computed using the time spent engaged in seventeen activities, and multiplying the time spent by the resting metabolic rate (MET score) specific for each activity ${ }^{(18)}$. The MET-hours for all activities were combined to obtain a value of total weekly MET-hours, which adequately correlated with energy expenditure measured by triaxial accelerometer in a validation subsample of the cohort ${ }^{(19)}$.

\section{Assessment of the outcome}

Participants' weight was recorded at baseline and every 2 years during follow-up. The reliability and validity of self-reported weight were previously assessed in a subsample of the cohort and was found to be highly correlated $(r=0.99)$, with a mean relative error in self-reported weight of $1.45 \%{ }^{(20)}$

The outcomes were: (i) change per year in body weight (and BMI) during follow-up as a continuous variable, calculated as the difference between the last answered questionnaire and the baseline questionnaire divided by the years of follow-up; (ii) a mean increment in body 
weight per year of at least $2 \mathrm{~kg}$ during follow-up; and (iii) incident overweight/obesity (participants with BMI $<25$ $\mathrm{kg} / \mathrm{m}^{2}$ at baseline and $\mathrm{BMI} \geq 25 \mathrm{~kg} / \mathrm{m}^{2}$ at follow-up).

\section{Statistical analyses}

Least-squares regression models were used to evaluate the association between eating out and weight change per year during follow-up. To estimate adjusted differences in weight and BMI changes per year between categories of eating out, we calculated adjusted regression coefficients (and their 95\% confidence intervals) in a multiple regression model, using non-eating-out consumers as the reference category.

Non-conditional logistic regression models were fit to assess the relationship between eating out and the risk of gaining $2 \mathrm{~kg}$ or more per year.

After excluding overweight/obese participants at baseline ( $n$ 2608), we assessed the hazard ratio of incident overweight/obesity (BMI $\geq 25 \mathrm{~kg} / \mathrm{m}^{2}$ ) for the different categories of eating-out consumers using a Cox proportional hazards analysis.

All analyses were adjusted for age, sex, physical activity, smoking, and other potential dietary and non-dietary confounders based on the previous scientific literature such as fibre intake, alcohol intake, total energy intake, years of education, smoking during follow-up, following any special diet and baseline BMI, except when we evaluated BMI change over time.

The $P$ for trend was calculated by introducing the categories of eating out as a continuous variable in the models. We evaluated effect modification through product terms.

All $P$ values presented are two-tailed; $P<0.05$ was considered statistically significant. Analyses were performed using the SPSS statistical software package version 15•0 (SPSS Inc., Chicago, IL, USA).

\section{Results}

The average follow-up was $4 \cdot 4(\mathrm{SD} 1 \cdot 7)$ years. The mean weight change during follow-up was $+0 \cdot 3$ (SD 1.4) $\mathrm{kg}$ per year among 9182 participants (mean age 36.7 (SD 11.4) years) of the SUN cohort. About $27 \%$ of participants reported eating away from home at least twice or more per week.

Eating-out consumers were younger, they were more likely to be male participants and smokers, had higher baseline weight and BMI, but were more physically active. Eating meals away from home was associated with relatively higher intakes of trans fats and alcohol, but with lower intakes of monounsaturated fats, fibre and carbohydrates. In relation to food consumption, participants who ate more frequently away from home consumed less vegetables, fruits, legumes and low-fat dairy products and more soft drinks, juices, red meat, fast food and processed meat (Table 1).
Eating-out consumers had a statistically significant higher average weight gain and BMI gain per year during followup in the multivariate-adjusted analysis (Table 2). Similarly, they had a higher risk of gaining $\geq 2 \mathrm{~kg}$ /year in the multivariate-adjusted analysis ( $P$ for trend $=0 \cdot 001$; Table 3 ). There were no significant differences in the prediction of weight gain between sexes ( $P$ value for interaction $=0 \cdot 85$ ). After excluding participants who were overweight/obese at baseline, we identified 855 new cases of overweight/obesity among 6574 participants. The habit of eating meals more frequently away from home was significantly associated with a higher risk of becoming overweight/obese during follow-up in the multivariate-adjusted analysis (Table 4).

When we conducted sensitivity analyses including those participants with chronic diseases at baseline or during follow-up ( $n$ 1085), the results pointed in the same direction (data not shown).

To address the issue of the regression towards the mean we stratified the results according to previous weight change in the last 5 years before the baseline questionnaire. Those participants who gained $3 \mathrm{~kg}$ or more of body weight in the previous 5 years showed a statistically significant association between eating out and weight gain (adjusted difference $=+242 \mathrm{~g} /$ year; 95\% CI +106 , $+379 \mathrm{~g}$ / year). On the contrary, those with weight losses of $3 \mathrm{~kg}$ or more in the previous 5 years showed a lower magnitude for the association that was not statistically significant (adjusted difference $=+149 \mathrm{~g} /$ year; $95 \% \mathrm{CI}-24,+322 \mathrm{~g}$ /year; $P$ for interaction $=0 \cdot 10$; data not shown).

\section{Discussion}

In the current prospective study, a higher frequency of away-from-home meals was associated with higher bodyweight gain and higher risk of becoming overweight/ obese during an average 4•4-year follow-up among healthy middle-aged Spanish university graduates.

This finding is consistent with previous research conducted in the USA. Several cross-sectional studies have evaluated the association between the habit of eating out and body weight. In 16103 participants in the Continuing Survey of Food Intake by Individuals, the authors found a significant positive relationship between BMI and consumption of food away from home in the past $24 \mathrm{~h}$ period $^{(21)}$. McCrory and colleagues reported that the frequency of consuming food from restaurants was positively associated with body fatness measured by hydrostatic weighing among seventy-three adults ${ }^{(22)}$. Regarding prospective studies, some of them have specifically assessed fast-food consumption. Among them, the Pound of Prevention Study found that the frequency of fast-food restaurant visits was associated with increases in body weight over a 3-year period in a sample of 891 adult women ${ }^{(23)}$. In a young population, the results from 3031 participants of the CARDIA (Coronary Artery Risk 
Table 1 Characteristics according to baseline frequency of eating out in 9182 participants from the SUN (Seguimiento Universidad de Navarra) Study, October 2007

\begin{tabular}{|c|c|c|c|c|c|c|c|}
\hline & \multicolumn{2}{|c|}{$\begin{array}{l}\text { Not eating out (never/almost } \\
\text { never to } 1-3 \text { times per month) }\end{array}$} & \multicolumn{2}{|c|}{$\begin{array}{l}\text { Eating out ( } 1 \text { time } \\
\text { per week) }\end{array}$} & \multicolumn{2}{|c|}{$\begin{array}{l}\text { Eating out ( } 2 \text { or more } \\
\text { times per week) }\end{array}$} & \multirow[b]{2}{*}{$P$ value* } \\
\hline & $n$ or Mean & $\%$ or SD & $n$ or Mean & $\%$ or SD & $n$ or Mean & $\%$ or SD & \\
\hline Participants & 4582 & $49 \cdot 9$ & 2086 & $22 \cdot 7$ & 2514 & $27 \cdot 4$ & \\
\hline Weight difference (kg/year) & 0.25 & $1 \cdot 35$ & 0.28 & $1 \cdot 33$ & 0.38 & $1 \cdot 41$ & \\
\hline Weight gain $\geq 2 \mathrm{~kg} /$ year $(n, \%)$ & 318 & $6 \cdot 9$ & 172 & $8 \cdot 2$ & 245 & $9 \cdot 7$ & $<0.001$ \\
\hline BMI difference $\left(\mathrm{kg} / \mathrm{m}^{2}\right)$ & +0.09 & 0.51 & $+0 \cdot 10$ & 0.46 & $+0 \cdot 16$ & 0.87 & $<0.001$ \\
\hline Incident overweight/obesity† (\%) & - & $12 \cdot 0$ & - & $12 \cdot 8$ & - & $15 \cdot 2$ & 0.005 \\
\hline Age (years) & $37 \cdot 4$ & $11 \cdot 9$ & $35 \cdot 7$ & $11 \cdot 3$ & $36 \cdot 0$ & $10 \cdot 4$ & $<0.001$ \\
\hline Female $(n, \%)$ & 2965 & $64 \cdot 7$ & 1229 & $58 \cdot 9$ & 1197 & $47 \cdot 6$ & $<0.001$ \\
\hline Baseline BMI (kg/m²) & $23 \cdot 1$ & 3.6 & $23 \cdot 3$ & 3.7 & $23 \cdot 6$ & $3 \cdot 8$ & $<0.001$ \\
\hline Baseline weight $(\mathrm{kg})$ & $65 \cdot 5$ & $12 \cdot 7$ & $67 \cdot 2$ & $13 \cdot 5$ & $69 \cdot 4$ & $14 \cdot 0$ & $<0.001$ \\
\hline Physical activity (MET $\times$ h/week) & $23 \cdot 8$ & $20 \cdot 6$ & $24 \cdot 5$ & $21 \cdot 3$ & $25 \cdot 4$ & $23 \cdot 2$ & 0.012 \\
\hline Smoking & & & & & & & 0.016 \\
\hline Current smokers $(n, \%)$ & 1043 & $22 \cdot 8$ & 517 & $24 \cdot 8$ & 611 & $24 \cdot 3$ & \\
\hline Former smokers $(n, \%)$ & 1338 & $29 \cdot 2$ & 589 & $28 \cdot 2$ & 648 & $25 \cdot 8$ & \\
\hline University education (years) & 4.9 & 1.5 & $5 \cdot 1$ & $1 \cdot 6$ & $5 \cdot 3$ & $1 \cdot 7$ & $<0.001$ \\
\hline Total energy intake $(\mathrm{kJ} / \mathrm{d})$ & 9916 & 2519 & 9942 & 2521 & 9955 & 2638 & 0.812 \\
\hline Total fat intake ( $\%$ of energy) & $36 \cdot 6$ & $6 \cdot 7$ & $37 \cdot 0$ & $6 \cdot 4$ & $36 \cdot 5$ & $6 \cdot 3$ & 0.051 \\
\hline SFA intake (\% of energy) & $12 \cdot 5$ & $3 \cdot 2$ & $12 \cdot 8$ & $3 \cdot 1$ & $12 \cdot 7$ & $3 \cdot 1$ & 0.003 \\
\hline MUFA intake (\% of energy) & $15 \cdot 8$ & $3 \cdot 8$ & $15 \cdot 9$ & $3 \cdot 6$ & $15 \cdot 6$ & $3 \cdot 6$ & 0.071 \\
\hline PUFA intake ( $\%$ of energy) & $5 \cdot 3$ & $1 \cdot 6$ & $5 \cdot 3$ & $1 \cdot 6$ & $5 \cdot 3$ & $1 \cdot 5$ & 0.924 \\
\hline Trans fat intake ( $\%$ of energy) & $0 \cdot 37$ & $0 \cdot 2$ & $0 \cdot 38$ & 0.2 & 0.39 & $0 \cdot 2$ & 0.002 \\
\hline Protein intake (\% of energy) & $18 \cdot 0$ & $3 \cdot \overline{2}$ & $18 \cdot 1$ & $3 \cdot 1$ & $17 \cdot 9$ & $3 \cdot 0$ & $0 \cdot 100$ \\
\hline $\begin{array}{l}\text { Carbohydrate intake (\% of } \\
\text { energy) }\end{array}$ & $41 \cdot 1$ & $6 \cdot 9$ & $40 \cdot 2$ & $6 \cdot 6$ & $40 \cdot 3$ & $6 \cdot 8$ & $<0.001$ \\
\hline Fibre intake $(\mathrm{g} / \mathrm{d})$ & $27 \cdot 9$ & $12 \cdot 3$ & $26 \cdot 3$ & $10 \cdot 9$ & $25 \cdot 1$ & $11 \cdot 2$ & $<0.001$ \\
\hline Alcohol intake (g/d) & $5 \cdot 3$ & $8 \cdot 7$ & $7 \cdot 0$ & $9 \cdot 5$ & $8 \cdot 9$ & $12 \cdot 4$ & $<0.001$ \\
\hline Snacking between meals ( $n, \%)$ & 1527 & $33 \cdot 6$ & 731 & $35 \cdot 5$ & 850 & $34 \cdot 1$ & 0.316 \\
\hline Glycaemic load & $180 \cdot 8$ & $66 \cdot 9$ & $175 \cdot 6$ & $63 \cdot 8$ & $176 \cdot 9$ & $66 \cdot 9$ & 0.004 \\
\hline \multicolumn{8}{|l|}{$\begin{array}{l}\text { Consumption of food groups } \\
\text { (servings/week) }\end{array}$} \\
\hline Vegetables & $15 \cdot 9$ & $10 \cdot 2$ & $15 \cdot 4$ & $9 \cdot 9$ & $14 \cdot 4$ & $8 \cdot 9$ & $<0.001$ \\
\hline Fruits & $17 \cdot 2$ & $14 \cdot \overline{4}$ & $15 \cdot 6$ & $11 \cdot 8$ & $14 \cdot 5$ & 11.9 & $<0.001$ \\
\hline Legumes & $2 \cdot 8$ & $2 \cdot 3$ & $2 \cdot 6$ & $1 \cdot 7$ & $2 \cdot 5$ & $1 \cdot 7$ & $<0.001$ \\
\hline Whole dairy products & $12 \cdot 2$ & $9 \cdot 6$ & $12 \cdot 1$ & $9 \cdot 3$ & $12 \cdot 0$ & $8 \cdot 8$ & 0.660 \\
\hline Low-fat dairy products & $9 \cdot 1$ & $10 \cdot 2$ & $9 \cdot 4$ & $10 \cdot 3$ & $8 \cdot 5$ & $9 \cdot 3$ & 0.014 \\
\hline Fish & $4 \cdot 8$ & $2 \cdot 9$ & $5 \cdot 0$ & $2 \cdot 8$ & $5 \cdot 0$ & $3 \cdot 1$ & $<0.001$ \\
\hline Chocolates & $2 \cdot 7$ & $3 \cdot 3$ & $2 \cdot 9$ & $3 \cdot 2$ & $2 \cdot 9$ & $3 \cdot 1$ & 0.027 \\
\hline Soft drinks & $1 \cdot 8$ & $4 \cdot 0$ & $2 \cdot 5$ & $4 \cdot 6$ & $2 \cdot 8$ & $4 \cdot 4$ & $<0.001$ \\
\hline Juices & $2 \cdot 8$ & $3 \cdot 8$ & $3 \cdot 2$ & $4 \cdot 4$ & $3 \cdot 4$ & $4 \cdot 5$ & $<0.001$ \\
\hline Alcoholic beverages & $3 \cdot 2$ & $5 \cdot 6$ & $4 \cdot 3$ & $6 \cdot 2$ & $5 \cdot 4$ & $7 \cdot 8$ & $<0.001$ \\
\hline Red meat & $3 \cdot 7$ & $2 \cdot 1$ & $3 \cdot 8$ & $2 \cdot 1$ & 3.9 & $2 \cdot 3$ & $<0.001$ \\
\hline Fast food $\neq$ & $1 \cdot 2$ & $1 \cdot 2$ & $1 \cdot 3$ & $1 \cdot 2$ & $1 \cdot 4$ & $1 \cdot 3$ & $<0.001$ \\
\hline Processed meat & $6 \cdot \overline{3}$ & $4 \cdot 1$ & $6 \cdot 7$ & $4 \cdot \overline{3}$ & $6 \cdot 4$ & $4 \cdot 3$ & 0.002 \\
\hline
\end{tabular}

MET, metabolic equivalent task.

Continuous variables are expressed as means and standard deviations; categorical variables as $n$ and \%.

${ }^{*} P$ value was calculated by ANOVA for continuous variables and the $\chi^{2}$ test for categorical variables.

tIncident overweight/obesity: percentage of people with BMI $<25 \mathrm{~kg} / \mathrm{m}^{2}$ at baseline with $\mathrm{BMI} \geq 25 \mathrm{~kg} / \mathrm{m}^{2}$ at follow-up.

†Sum of hamburgers, sausages and pizza.

Development in Young Adults) study reported a strong positive association between frequency of fast-food consumption and weight gain during 15-year follow-up ${ }^{(24)}$. Similarly, a study conducted among 101 healthy girls from two schools near Boston reported that participants who ate quick-service food with a frequency of at least once weekly were more likely to increase their relative BMI over time ${ }^{(25)}$. Similarly, results from the Growing Up Today Study showed that, in a cohort of 7745 girls and 6610 boys aged 9 to 14 years, those who increased their consumption of fried food away from home over 1 year gained weight above the expected gain from normal growth $^{(26)}$.
However, our results differed from those of a recent European ecological study that did not find any effect on obesity on the part of the food share expenditure spent on food eaten away from home, suggesting that the type or quality of food eaten away from home in the USA and Europe is different, as pointed out by the authors. Nevertheless, differences between study designs can contribute to obtaining different results. As the authors reported, their finding was based on rough measures and needed more research with data collected on an individual basis ${ }^{(27)}$. A recent cross-sectional study ${ }^{(12)}$ conducted in Spain also did not find any positive association between away-from-home eating and obesity. However, 
Table 2 Estimates $^{*}$ (regression coefficients, $\beta$ ) of subsequent weight change and BMI change per year according to eating out in 9182 participants of the SUN (Seguimiento Universidad de Navarra) Study, October 2007

\begin{tabular}{|c|c|c|c|c|c|c|c|}
\hline \multirow{3}{*}{ Participants, $n$} & \multicolumn{2}{|c|}{$\begin{array}{l}\text { Not eating out (never/almost } \\
\text { never to } 1-3 \text { times per month) }\end{array}$} & \multicolumn{2}{|c|}{$\begin{array}{l}\text { Eating out ( } 1 \text { time } \\
\text { per week) }\end{array}$} & \multicolumn{2}{|c|}{$\begin{array}{l}\text { Eating out ( } 2 \text { or more } \\
\text { times per week) }\end{array}$} & \multirow[t]{3}{*}{$\begin{array}{l}P \text { for } \\
\text { trend }\end{array}$} \\
\hline & & & & 2086 & & 2514 & \\
\hline & Mean & SD & Mean & SD & Mean & SD & \\
\hline \multirow[t]{2}{*}{ Weight change per year $(\mathrm{g})$} & +253 & $1 \cdot 35$ & +284 & $1 \cdot 33$ & +384 & $1 \cdot 41$ & \\
\hline & $\beta$ & $95 \% \mathrm{Cl}$ & $\beta$ & $95 \% \mathrm{Cl}$ & $\beta$ & $95 \% \mathrm{Cl}$ & \\
\hline \multirow[t]{2}{*}{$\begin{array}{l}\text { Age- and sex-adjusted } \\
\text { Multivariate }{ }^{\star} \text {-adjusted }\end{array}$} & $\begin{array}{l}0 \\
0\end{array}$ & $\begin{array}{l}\text { ref } \\
\text { ref }\end{array}$ & $\begin{array}{l}+22 \\
+15\end{array}$ & $\begin{array}{l}-49,+92 \\
-55,+86\end{array}$ & $\begin{array}{l}+135 \\
+129\end{array}$ & $\begin{array}{l}+68,+202 \\
+62,+197\end{array}$ & $\begin{array}{l}<0.001 \\
<0.001\end{array}$ \\
\hline & Mean & SD & Mean & SD & Mean & SD & \\
\hline \multirow[t]{2}{*}{ BMI change per year $\left(\mathrm{kg} / \mathrm{m}^{2}\right)$} & +0.09 & 0.51 & $+0 \cdot 10$ & 0.46 & $+0 \cdot 16$ & 0.87 & \\
\hline & $\beta$ & $95 \% \mathrm{Cl}$ & $\beta$ & $95 \% \mathrm{Cl}$ & $\beta$ & $95 \% \mathrm{Cl}$ & \\
\hline \multicolumn{8}{|l|}{ Differences in BMI change $\left(\mathrm{kg} / \mathrm{m}^{2}\right.$ per year) } \\
\hline Age- and sex-adjusted & 0 & ref & +0.01 & $-0.03,+0.04$ & +0.07 & $+0.04,+0.10$ & $<0.001$ \\
\hline
\end{tabular}

ref, reference category.

${ }^{*}$ Multivariate models adjusted for age, sex, baseline smoking, snacking, leisure-time physical activity (quartiles), fibre intake, alcohol intake, total energy intake, years of education, smoking during follow-up, following any special diet and baseline BMI.

Table 3 Odds ratios of gaining $2 \mathrm{~kg}$ or more per year according to eating out in 9182 participants of the SUN (Seguimiento Universidad de Navarra) Study, October 2007

\begin{tabular}{|c|c|c|c|c|c|c|c|}
\hline \multirow{4}{*}{$\begin{array}{l}\text { Participants, } n \\
\text { Cases, } n \\
\text { Cases, \% }\end{array}$} & \multicolumn{2}{|c|}{$\begin{array}{l}\text { Not eating out (never/almost } \\
\text { never to } 1-3 \text { times per month) }\end{array}$} & \multicolumn{2}{|c|}{$\begin{array}{l}\text { Eating out ( } 1 \text { time } \\
\text { per week) }\end{array}$} & \multicolumn{2}{|c|}{$\begin{array}{l}\text { Eating out ( } 2 \text { or more } \\
\text { times per week) }\end{array}$} & $\begin{array}{l}P \text { for } \\
\text { trend }\end{array}$ \\
\hline & \multirow{3}{*}{\multicolumn{2}{|c|}{$\begin{array}{c}4582 \\
318 \\
6.9\end{array}$}} & \multirow{3}{*}{\multicolumn{2}{|c|}{$\begin{array}{c}2086 \\
172 \\
8 \cdot 2\end{array}$}} & \multirow{3}{*}{\multicolumn{2}{|c|}{$\begin{array}{c}2514 \\
245 \\
9 \cdot 7\end{array}$}} & \\
\hline & & & & & & & \\
\hline & & & & & & & \\
\hline & OR & $95 \% \mathrm{Cl}$ & OR & $95 \% \mathrm{Cl}$ & OR & $95 \% \mathrm{Cl}$ & \\
\hline Age- and sex-adjusted & 1.00 & ref & $1 \cdot 16$ & $0.95,1.41$ & $1 \cdot 39$ & $1 \cdot 16,1 \cdot 65$ & $<0.001$ \\
\hline Multivariate*-adjusted & 1.00 & ref & $1 \cdot 12$ & $0.92,1.37$ & $1 \cdot 36$ & $1 \cdot 13,1 \cdot 63$ & 0.001 \\
\hline
\end{tabular}

ref, reference category.

*Multivariate model adjusted for age, sex, baseline smoking, snacking, leisure-time physical activity (quartiles), fibre intake, alcohol intake, total energy intake, years of education, smoking during follow-up, following any special diet and baseline BMI.

Table 4 Hazard ratios (HR) of incident overweight/obesity $\left(\mathrm{BMI} \geq 25 \mathrm{~kg} / \mathrm{m}^{2}\right)$ according to eating out in 6574 participants free of overweight/ obesity at baseline from the SUN (Seguimiento Universidad de Navarra) Study, October 2007

\begin{tabular}{|c|c|c|c|c|c|c|c|}
\hline \multirow[b]{2}{*}{$\begin{array}{l}\text { Cases, } n \\
\text { Person-years of follow-up }\end{array}$} & \multicolumn{2}{|c|}{$\begin{array}{l}\text { Not eating out (never/almost never } \\
\text { to } 1-3 \text { times per month) }\end{array}$} & \multicolumn{2}{|c|}{$\begin{array}{c}\text { Eating out } \\
\text { (1 time per week) }\end{array}$} & \multicolumn{2}{|c|}{$\begin{array}{c}\text { Eating out ( } 2 \text { or more times } \\
\text { per week) }\end{array}$} & \multirow[t]{2}{*}{$P$ for trend } \\
\hline & & & & $\begin{array}{c}190 \\
6569\end{array}$ & & & \\
\hline & $\mathrm{HR}$ & $95 \% \mathrm{Cl}$ & $\mathrm{HR}$ & $95 \% \mathrm{Cl}$ & $\mathrm{HR}$ & $95 \% \mathrm{Cl}$ & \\
\hline $\begin{array}{l}\text { Age- and sex-adjusted } \\
\text { Multivariate*-adjusted }\end{array}$ & $\begin{array}{l}1.00 \\
1.00\end{array}$ & $\begin{array}{l}\text { ref } \\
\text { ref }\end{array}$ & $\begin{array}{l}1 \cdot 11 \\
1 \cdot 22\end{array}$ & $\begin{array}{ll}0.93,1.32 \\
1.02 & 1.45\end{array}$ & $\begin{array}{l}1 \cdot 22 \\
1 \cdot 33\end{array}$ & $\begin{array}{l}1.04,1.43 \\
1.13,1.57\end{array}$ & $\begin{array}{r}0.013 \\
<0.001\end{array}$ \\
\hline
\end{tabular}

ref, reference category.

*Multivariate model adjusted for age, sex, baseline smoking, snacking, leisure-time physical activity (quartiles), fibre intake, alcohol intake, total energy intake, years of education, smoking during follow-up, following any special diet and baseline BMI.

this result could be explained by the limitations of its cross-sectional design. Subjects with higher BMI, concerned about putting on weight, may have restricted the number of meals they ate away from home. In fact, the adjusted results from our cross-sectional analyses showed no association between eating out and BMI. Moreover, a Spanish cross-sectional study ${ }^{(6)}$ reported that fastfood consumption was associated with higher BMI in 
agreement with our prospective results. The differences between the two previous cross-sectional studies can be explained by the different designs and also because they used a different definition of the exposure (eating away from home $v$. fast-food consumption).

The frequency of eating out in our cohort was higher than the frequency observed in the previous cross-sectional Spanish studies ${ }^{(6,12)}$, probably because our participants were younger, and in the study conducted by Schröder et al. $^{(6)}$ only fast-food consumption was assessed. However, our frequency of consumption was in agreement with another previous study conducted in the USA. The frequency of food purchased away from home in Thompson et al.'s study ${ }^{(25)}$ was on average 1.96 times per week in comparison with 1.68 times per week in our cohort.

The partially hydrogenated oils used in some restaurants, the large portion sizes usually served (leading to a positive energy balance) and the frequent presence of energy-dense foods (with the same effect) may be potential reasons to explain why restaurant food consumption could promote weight gain ${ }^{(11,28)}$.

In addition, restaurant meals tend to be higher in fat and lower in fibre content. Fibre intake has been shown to induce a greater sensation of satiety and increase insulin sensitivity, a response linked to decreases in hunger and subsequently energy intake. One of the salient characteristics of the traditional Mediterranean food pattern is the daily consumption of fresh fruits as the usual dessert. This characteristic is very likely to be lost when the meals are eaten in a restaurant. This is true not only for fast-food outlets but also for restaurants more in line with the Mediterranean culinary tradition.

In fact, in our cohort, consumers of away-from-home meals had not only more than one serving less of vegetables but also, more importantly, more than two servings less of fruits per week in comparison to non-eating-out consumers. It should also be noted that consumers of away-from-home meals consumed one more sugarsweetened soft drink and two more alcoholic beverages per week in comparison with non-eating-out consumers. All of the above aspects are very plausible explanations of our findings, because they are associated with weight gain in this cohort ${ }^{(29,30)}$ and in other populations ${ }^{(31,32)}$. Eating-out consumers presented less healthy dietary characteristics with a more overall energy-dense dietary pattern contributing to a positive energy balance, the ultimate driver of weight gain.

Furthermore, one of the most important differences between eating-out consumers and non-eating-out consumers found in our cohort is that the former had higher alcohol intake. This result is in agreement with a Dutch study reporting that in a representative sample population from The Netherlands, $45 \%$ of energy from alcohol was consumed out of the home ${ }^{(33)}$. This finding indicates that not only the food eaten at restaurants is important, but also that patterns of beverage consumption related to meals eaten in restaurants might play a major role in the development of overweight/obesity.

Eating and drinking out is part of the current lifestyle of Spaniards and other Mediterranean populations. This fact explains the importance of full-service restaurants in this geographical $\operatorname{area}^{(9)}$. In the last two decades, however, food patterns in most of the Mediterranean area have shifted to a more Westernized type, especially among the young population $^{(34,35)}$. We should bear in mind that the food service with the highest growth in Southern Europe during the last years has been fast-food restaurants ${ }^{(9)}$. In addition, full-service restaurants may lead to overconsumption not only because of the wide variety of palatable food served in large portions, but also because of the social facilitation of food intake as individuals tend to consume more food when eating in the presence of others $^{(36)}$.

Unfortunately, we do not have data about what types of restaurant food our subjects consumed, nor could the questionnaire identify the types of foods eaten away from home, nor if participants ate away from home for lunch or for dinner. This fact could contribute to the low differences in nutrient intakes between the three categories of eating out.

Although we found a significant association between eating away from home and weight gain, we observed modest differences in nutrient intakes and consumption of food groups between eating-out consumers and noneating-out consumers. There are several possible explanations for this finding. First, it has been proposed that small changes in behaviour such as eating a few less bites at each meal can be the key for the prevention of weight gain ${ }^{(37)}$. Low amounts of positive energy imbalance every day or every week can have a great impact on long-term weight gain ${ }^{(38)}$. Second, we have to take into account that an FFQ presents some degree of measurement error, especially for total energy intake, inherent to the methods of nutritional epidemiology ${ }^{(39)}$. In addition, among those participants who ate away from home, since they probably did not prepare their food, their measurement error (under-reporting) in answering the FFQ may be greater. In addition, the standard serving sizes used in the FFQ might underestimate portions provided when eating out. In this context, there are data from the USA showing an increase in portion sizes over time ${ }^{(40)}$. This issue may explain that the small differences, although significant, in total energy intake and food group intakes between groups have resulted in differences in weight gain (positive energy balance), due to the fact that the real differences between groups were probably larger than observed.

The present study was observational, and the possibility of residual confounding or collinearity among variables may limit the inference of causality. The consumption of meals in restaurants may be one in a cluster of other interrelated behaviours that may contribute to excess weight gain and obesity. Nevertheless, our results 
might underestimate the true magnitude of the effect through adjustment for some covariates that might be on the causal pathway ${ }^{(41)}$. The possibility of a measurement error would also lead to an underestimation of the true effects. Another aspect to address is the possible existence of regression to the mean: in the likelihood of higher weight gains in those participants who had decreased their weight before the follow-up and vice versa, it could be thought greater losses in those participants who had increased their weight before starting the follow-up could be a consequence of regression to the mean. However, the results from the stratified analyses for previous weight gain did not support this possibility because those who gained weight in the previous 5 years, before the baseline questionnaire, presented the highest weight gain during follow-up. Similar results were observed in the Danish MONICA (Monitoring Trends and Determinants in Cardiovascular Disease) project when weight gain was independent of the weight changes in the previous 5 years ${ }^{(42)}$.

In spite of these potential limitations, the evidence derived from our results should be helpful for health policy makers in their efforts to tackle the growing obesity epidemic in Europe, especially in the Mediterranean countries. Profit margins were found to be a key driver of decisions to offer healthier food options to consumers after interviewing senior menu development and marketing executives at leading full-service and limitedservice chain restaurants in the $\mathrm{USA}^{(42)}$. A recent article found that fast-food chains have responded little or not at all to calls to voluntarily reduce the portion size of their products in the USA ${ }^{(43)}$. Therefore, without an increase in consumer demand, it seems unlikely that the restaurant industry will foster the offering of healthy food choices unless different approaches through legal measures and consumers' efforts are applied, as has happened in New York City ${ }^{(44)}$. Meanwhile, the general population should be aware of the potential problems of eating out for maintaining a healthy weight and take into account possible alternatives such as the habit of splitting an entrée with a friend or eating half of the meal and asking for a carry-out container for the rest.

In conclusion, a high frequency of eating away-fromhome meals has been associated with a higher subsequent body weight, and with an increase in the risk of becoming overweight/obese. This emerging trend is thus a potential risk factor to be considered in the battle against obesity in Europe.

However, more research is needed to better classify the restaurant types, and better data are required on the effect of food that is home prepared or prepared out of home, independently of the place where it is eaten. At the same time, it would be important to evaluate if incentive measures for promoting a healthier menu in food establishments would lead to better health outcomes and prevent further weight gain.

\section{Acknowledgements}

The SUN Study has received funding from the Spanish Ministry of Health (Grants PI030678, PI040233, PI070240, PI081943, RD06/0045 and G03/140), the Navarra Regional Government (PI41/2005, PI36/2008) and the University of Navarra. There are no conflicts of interests. M.B.-R. participated in the conception and design, statistical analyses and data interpretation, manuscript drafting and critical revision of the manuscript. F.J.B.-G. and A.S.-V. participated in the statistical analyses, data interpretation and critical revision. A.M. and J.A.M. participated in the data interpretation and critical revision. M.A.M.-G. participated in the funding, concept and design, data interpretation and critical revision. All authors contributed to the final version of the article. We thank participants of the SUN Project for their continued cooperation and participation. The scientific, administrative, technical and material support of other members of the SUN Study Group is acknowledged.

\section{References}

1. Trichopoulou A, Costacou T, Bamia C et al. (2003) Adherence to a Mediterranean diet and survival in a Greek population. N Engl J Med 348, 2599-2608.

2. Keys A (1995) Mediterranean diet and public health: personal reflections. Am J Clin Nutr 61, Suppl. 6, S1321-S1323.

3. Tortosa A, Bes-Rastrollo M, Sanchez-Villegas A et al. (2007) Mediterranean diet inversely associated with the incidence of metabolic syndrome: the SUN prospective cohort. Diabetes Care 30, 2957-2959.

4. Estruch R, Martinez-Gonzalez MA, Corella D et al. (2006) Effects of a Mediterranean-style diet on cardiovascular risk factors: a randomized trial. Ann Intern Med 145, 1-11.

5. Lin BH \& Frazao E (1998) Nutritional quality of foods at and away from home. Food Rev 22, 39-47.

6. Schröder H, Fito M \& Covas MI (2007) Association of fast food consumption with energy intake, diet quality, body mass index and the risk of obesity in a representative Mediterranean population. Br J Nutr 98, 1274-1280.

7. Gutierrez-Fisac JL, Royo-Bordonada MA \& RodriguezArtalejo F (2006) Health risks associated with Western diet and sedentariness: the obesity epidemia. Gac Sanit 20, Suppl. 1, S48-S54.

8. Spanish Ministry of Agriculture, Fishing and Feeding (2007) La alimentación en España, 2006 (The feeding in Spain, 2006). http://www.mapa.es/es/alimentacion/pags/consumo/ libro/2006/libro.htm (accessed April 2009).

9. Becker N (2007) Consumer foodservice in southern Europe. Eur Retail Digest 53, 44-47.

10. Groves T (2006) Pandemic obesity in Europe. BMJ 333, 1081.

11. Kral TVE, Roe LS \& Rolls BJ (2004) Combined effects of energy density and portion size on energy intake in women. Am J Clin Nutr 79, 962-968.

12. Marin-Guerrero AC, Gutierrez-Fisac JL, Guallar-Castillon P et al. (2008) Eating behaviours and obesity in the adult population of Spain. Br J Nutr 100, 1142-1148.

13. Segui-Gomez M, de la Fuente C, Vazquez Z et al. (2006) Cohort profile: the 'Seguimiento Universidad de Navarra' (SUN) study. Int J Epidemiol 35, 1417-1422. 
14. Willett WC (1998) Issues in analysis and presentation of dietary data. In Nutritional epidemiology, 2nd ed., pp. 321-346 [WC Willett, editor]. New York: Oxford University Press.

15. Martin-Moreno JM, Boyle P, Gorgojo L et al. (1993) Development and validation of a food frequency questionnaire in Spain. Int J Epidemiol 22, 512-519.

16. Mataix J (2003) Tabla de composición de alimentos (Food Composition Tables), 4th ed. Granada: Universidad de Granada.

17. Moreiras O (2005) Tablas de composición de alimentos (Food Composition Tables), 9th ed. Madrid: Ediciones Piramide.

18. Ainsworth BE, Haskell WL, Whitt MC et al. (2000) Compendium of physical activities: an update of activity codes and MET intensities. Med Sci Sports Exerc 32, Suppl. 9, S492-S504.

19. Martinez-Gonzalez MA, Lopez-Fontana C, Varo JJ et al (2005) Validation of the Spanish version of the physical activity questionnaire used in the Nurses' Health Study and the Health Professionals' Follow-up Study. Public Health Nutr 8, 920-927.

20. Bes-Rastrollo M, Perez JR, Sanchez-Villegas A et al. (2005) Validation of the self-reported weight and body mass index of the participants in a cohort of university graduates. Rev Esp Obes 3, 352-358.

21. Binkley JK, Eales J \& Jekanowski M (2000) The relation between dietary change and rising US obesity. Int J Obes Relat Metab Disord 24, 1032-1039.

22. McCrory MA, Fuss PJ, Hays NP et al. (1999) Overeating in America: association between restaurant food consumption and body fatness in healthy adult men and women ages 19 to 80. Obes Res 7, 564-571.

23. French SA, Harnack L \& Jeffery RW (2000) Fast food restaurant use among women in the Pound of Prevention study: dietary, behavioural and demographic correlates. Int J Obes Relat Metab Disord 24, 1353-1359.

24. Pereira MA, Kartashov AI, Ebbeling CB et al. (2005) Fast-food habits, weight gain, and insulin resistance (the CARDIA study): a 15-year prospective analysis. Lancet 365, 36-42.

25. Thompson OM, Ballew C, Resnicow K et al. (2004) Food purchased away from home as a predictor of change in BMI z-score among girls. Int J Obes (Lond) 28, 282-289.

26. Taveras EM, Berkey CS, Rifas-Shiman SL et al. (2005) Association of consumption of fried food away from home with body mass index and diet quality in older children and adolescents. Pediatrics 116, 518-524.

27. Michaud PC, van Soest AHO \& Andreyeva T (2007) Crosscountry variation in obesity patterns among older Americans and Europeans. Forum Health Econ Policy 10, issue 2 (Aging and Medical Care Costs), article 8; available at http://www.bepress.com/fhep/10/2/8

28. Field AE, Willett WC, Lissner L et al. (2007) Dietary fat and weight gain among women in the Nurses' Health Study. Obesity (Silver Spring) 15, 967-976.
29. Bes-Rastrollo M, Martinez-Gonzalez MA, Sanchez-Villegas A et al. (2006) Association of fiber intake and fruit/ vegetable consumption with weight gain in a Mediterranean population. Nutrition 22, 504-511.

30. Bes-Rastrollo M, Sanchez-Villegas A, Gomez-Gracia E et al. (2006) Predictors of weight gain in a Mediterranean cohort: the Seguimiento Universidad de Navarra Study. Am J Clin Nutr 83, 362-370.

31. Vioque J, Weinbrenner T, Castello A et al. (2008) Intake of fruits and vegetables in relation to 10 -year weight gain among Spanish adults. Obesity (Silver Spring) 16, 664-670.

32. Malik VS, Schulze MB \& Hu FB (2006) Intake of sugarsweetened beverages and weight gain: a systematic review. Am J Clin Nutr 84, 274-288.

33. Kearney JM, Hulshof KF \& Gibney MJ (2001) Eating patterns - temporal distribution, converging and diverging foods, meals eaten inside and outside of the home implications for developing FBDG. Public Health Nutr $\mathbf{4}$, 693-698.

34. Garcia-Closas R, Berenguer A \& Gonzalez CA (2006) Changes in food supply in Mediterranean countries from 1961 to 2001. Public Health Nutr 9, 53-60.

35. Sanchez-Villegas A, Delgado-Rodriguez M, MartinezGonzalez MA et al. (2003) Gender, age, socio-demographic and lifestyle factors associated with major dietary patterns in the Spanish Project SUN (Seguimiento Universidad de Navarra). Eur J Clin Nutr 57, 285-292.

36. De Castro JM (1997) Socio-cultural determinants of meal size and frequency. Br J Nutr 77, Suppl. 1, S39-S55.

37. Hill JO, Wyatt HR, Reed GW et al. (2003) Obesity and the environment: where do we go from here? Science 299, 853-855.

38. Hill JO (2009) Can a small-changes approach help address the obesity epidemic? A report of the Joint Task Force of the American Society for Nutrition, Institute of Food Technologists, and International Food Information Council. Am J Clin Nutr 89, 477-484.

39. Kristal AR, Peters U \& Potter JD (2005) Is it time to abandon the food frequency questionnaire? Cancer Epidemiol Biomarkers Prev 14, 2826-2828.

40. Young LR \& Nestle M (2002) The contribution of expanding portion sizes to the US obesity epidemic. Am J Public Health 92, 246-249.

41. Shrier I \& Platt RW (2008) Reducing bias through directed acyclic graphs. BMC Med Res Methodol 8, 70.

42. Glanz K, Resnicow K, Seymour J et al. (2007) How major restaurant chains plan their menus. The role of profit, demand, and health. Am J Prev Med 32, 383-388.

43. Young LR \& Nestle M (2007) Portion sizes and obesity: responses of fast-food companies. J Public Health Policy 28, 238-248.

44. Anonymous (2006) Out of the frying pan... (Editorial). Lancet 368, 2106. 